\title{
Self-assembly of self-assembled molecular triangles
}

\author{
MILI C NARANTHATTA, V RAMKUMAR and DILLIP KUMAR CHAND* \\ Department of Chemistry, Indian Institute of Technology Madras, Chennai 600 036, India \\ e-mail: dillip@iitm.ac.in; dillipiitm@gmail.com
}

MS received 6 April 2014; revised 13 May 2014; accepted 14 May 2014

\begin{abstract}
A rare variety of self-assembled molecular triangle $\left.\left[\mathrm{Pd}_{3}(\text { bpy })_{3} \text { (imidazolate }\right)_{3}\right]\left(\mathrm{NO}_{3}\right)_{3}, \mathbf{1}$ is prepared by the combination of $\mathrm{Pd}(\mathrm{bpy})\left(\mathrm{NO}_{3}\right)_{2}$ with imidazole, at 1:1 ratio, in acetonitrile-water. Deprotonation of imidazole happened during the course of the complexation reaction where upon the metallomacrocycle is formed. The bowl-shaped trinuclear architecture of $\mathbf{1}$ is crafted with three peripheral bpy units capable of $\pi-\pi$ stacking interactions. While the solution state structure of $\mathbf{1}$ can be best described as a trinuclear complex, in the solidstate well-fashioned intermolecular $\pi-\pi$ and $\mathrm{CH}-\pi$ interactions are observed. Thus, in the solid-state further self-assembly of already self-assembled molecular triangle is witnessed. The triangular panels are arranged in a linear manner utilizing intermolecular $\pi-\pi$ interactions where upon two out of three bpy units of each molecule participated in the chain formation.
\end{abstract}

Keywords. Palladium(II); 2,2'-bipyridyl; imidazole; self-assembly; molecular triangle.

\section{Introduction}

The metal-directed self-assembly has provided powerful tools to construct finite architectures with well defined shapes and sizes and also the rational design in the self assembly has resulted in significant progress in recent years. ${ }^{1}$ These approaches involve mixing of chosen metal ions with a multidentate ligand in a specific ratio to afford infinite or finite self-assembled molecules. Apart from the synthesis and characterization of new self-assembled molecules, it is necessary to take into account the possible weak intermolecular interactions which contribute to the supramolecular association in the solid-state. The weak interactions encountered most often in the packing in solid-state are hydrogen bonding, ${ }^{2}$ and $\pi-\pi$ stacking. ${ }^{3}$ The formation of large crystalline systems depends upon these interactions.

Square planar Pd(II) component has been one of the favourite metal ions used for the self-assembly approach. ${ }^{1 \mathrm{a}-\mathrm{d}} \mathrm{A}$ variety of $\mathrm{Pd}(\mathrm{II})$ components are utilized to prepare discrete coordination cage type molecules upon complexation with suitably chosen ligands. Combination of a bis-monodentate ligand $\mathbf{L}$ with a cis-protected $\mathrm{Pd}(\mathrm{II})$ component $\mathrm{ML}^{\prime}$ results in $\mathrm{M}_{\mathrm{x}} \mathrm{L}_{\mathrm{x}}^{\prime} \mathrm{L}_{\mathrm{y}}$ type self-assembled compound having the general formula $\left[\mathrm{Pd}_{\mathrm{x}}(\mathrm{N}-\mathrm{N})_{\mathrm{x}}(\mathbf{L})_{\mathrm{y}}\right](\text { monoanion })_{2 \mathrm{x}} \cdot{ }^{1 \mathrm{a}-\mathrm{d}}$ In this formula "N-N" stands for a chelating bidentate ligand, e.g., ethylenediamine (en), tetramethylethylenediamine

*For correspondence (tmeda), 2,2'-bipyridine (bpy), and 1,10-phenanthroline (phen), etc. The synthesis and dynamic studies of a variety of designed $\mathrm{Pd}(\mathrm{II})$ cages are well studied ${ }^{1 \mathrm{a}-\mathrm{d}}$ but the crystal engineering of Pd(II)-based self-assembled coordination cages has been less explored. ${ }^{4}$ Recently we have been investigating the significance of these compounds in crystal engineering. We have reported a few binuclear self-assembled coordination complexes which undergo further self-assembly in solid-state by exploiting weak interactions such as $\mathrm{H}$-bonding and $\pi-\pi$ stacking. ${ }^{4 a, b}$ The $\pi-\pi$ stacking is exploited as the targeted intermolecular interactions in the designs. ${ }^{4 a, b}$ In previous reports, we considered some binuclear complexes for investigating the novel packing behaviours of the already self-assembled molecules and then studied the self-assembly of self-assembly phenomenon in the solid state. ${ }^{4 a, b}$ The self-assembly of self-assembly was formed due to the packing of the 'opened jaws type' complexes in a linear intermolecular locking fashion ${ }^{4 a}$ in one case. In another case 'steps type' complexes got packed in a 'toppled domino set' fashion. ${ }^{4 \mathrm{~b}}$ These targeted packing of molecules are obtained due to the presence of $\pi$-surfaces at the strategically located cisprotecting moieties located around the $\mathrm{Pd}(\mathrm{II})$ centres.

Study of the intermolecular interactions using trinuclear Pd(II) complex having suitably located $\pi$ surfaces could be a new and fascinating contribution to the crystal engineering. Thus we explored the solidstate packing behaviours of designed tri-nuclear $\mathrm{Pd}(\mathrm{II})$ based coordination complexes. Most of the complexes of general formula $\left[\mathrm{Pd}_{\mathrm{x}}(\mathrm{N}-\mathrm{N})_{\mathrm{x}}(\mathbf{L})_{\mathrm{y}}\right](\text { monoanion })_{2 \mathrm{x}}$, 
prepared using bis-monodentate ligands, are binuclear in nature whereas there are only a few trinuclear structures reported so far. ${ }^{1 \mathrm{~b}, 5,6}$ The trinuclear complexes are usually found in dynamic equilibrium with corresponding bi or tetra-nuclear complexes. ${ }^{1 \mathrm{~b}, 6}$ However, there are a few complexes that are isolated solely as trinuclear single discrete structure. ${ }^{5}$ We have prepared a new trinuclear compound $\left.\left[\mathrm{Pd}_{3}(\text { bpy })_{3} \text { (imidazolate }\right)_{3}\right]\left(\mathrm{NO}_{3}\right)_{3}$, 1 (figure 1a and scheme 1) to study the role of weak intermolecular interactions in the solid-state packing. It was anticipated that the judicial introduction of cisprotecting units, having $\pi$-surfaces, at the corners of a triangular architecture as in $\mathbf{1}$ should give rise to specific intermolecular interactions via $\pi-\pi$ stacking as shown in figure 1. There are two possible ways of arrangement of triangular units. These units can be associated in a circular fashion (figure 1b) and linear fashion (figure 1c) to give rise to a specific packing. During this study we observed the linear chain like arrangement as shown in figure $1 \mathrm{~b}$. The packing diagram in the crystal structure of $\mathbf{1}$ is analyzed to elaborate the roles played by weak interactions like $\pi-\pi$ and $\mathrm{CH}-\pi$ stacking interactions.

\section{Experimental}

\subsection{Materials}

$\mathrm{PdCl}_{2}$ was obtained from Aldrich, whereas $\mathrm{AgNO}_{3}$, imidazole $(\mathbf{L} \cdot \mathbf{H})$ and all the common solvents were obtained from Spectrochem, India. The deuterated solvent (DMSO- $d_{6}$ ) was obtained from Aldrich and Cambridge Isotope Laboratories. ${ }^{1} \mathrm{H}$ and all NMR spectral data were obtained from a Bruker $500 \mathrm{MHz}$ FT NMR spectrometer using external TMS in $\mathrm{CDCl}_{3}$ as reference. The mass spectrum was obtained from a Micromass Q-TOF Mass Spectrometer. The crystal structure was determined using a Bruker X8 Kappa XRD instrument. The cis-protected $\mathrm{Pd}(\mathrm{II})$ component was obtained following well-known processes. ${ }^{7}$ Imidazole was used as such for the complexation reaction without any purification.

\subsection{Synthesis of $\left[\mathrm{Pd}_{3}(\text { bpy })_{3}(\text { imidazolate })_{3}\right]\left(\mathrm{NO}_{3}\right)_{3}, \mathbf{1}$}

To a solution of $\mathrm{Pd}(\mathrm{bpy})\left(\mathrm{NO}_{3}\right)_{2}(11.0 \mathrm{mg} 0.025 \mathrm{mmol})$ in $1: 1$ acetonitrile-water $(3.0 \mathrm{~mL})$, imidazole, $\mathbf{L} \cdot \mathbf{H}$ $(1.76 \mathrm{mg}, 0.025 \mathrm{mmol})$ was added and the mixture was stirred at room temperature for $2 \mathrm{~h}$. The resulting solution was evaporated by standing at room temperature and dried under vacuum to afford a dark yellow solid as the product. Yield: (93\%). M.p.: $210^{\circ} \mathrm{C} .{ }^{1} \mathrm{H}$ NMR $\left(\delta 500 \mathrm{MHz}, \mathrm{DMSO}-d_{6}\right.$, external $\left.\mathrm{CDCl}_{3} / \mathrm{TMS}\right): 9.29\left(\mathrm{~d}, J=10 \mathrm{~Hz}, 2 \mathrm{H}, \mathrm{H}_{\mathrm{d}}\right), 9.03(\mathrm{t}$, $\left.J=10 \mathrm{~Hz}, 2 \mathrm{H}, \mathrm{H}_{\mathrm{c}}\right), 8.62\left(\mathrm{bs}, 2 \mathrm{H}, \mathrm{H}_{\mathrm{a}}\right), 8.35-8.32(\mathrm{~m}$, $2 \mathrm{H}, \mathrm{H}_{\mathrm{b}}$ ), 8.00-7.39 (broad signals, $2 \mathrm{H}, \mathrm{H}_{\mathrm{f}}$ ); ${ }^{13} \mathrm{C} \mathrm{NMR}$ $\left(125 \mathrm{MHz}, \mathrm{DMSO}-d_{6}\right.$, residual solvent) $\delta: 155.76$, $150.54,142.50,142.12,128.16,126.94,124.10$. ESIMS: $m / z=329$ and 525 corresponding to $\left[1-3 \mathrm{NO}_{3}\right]^{3+}$ and $\left[\mathbf{1}-2 \mathrm{NO}_{3}\right]^{2+}$, respectively. Single crystals were

(b)

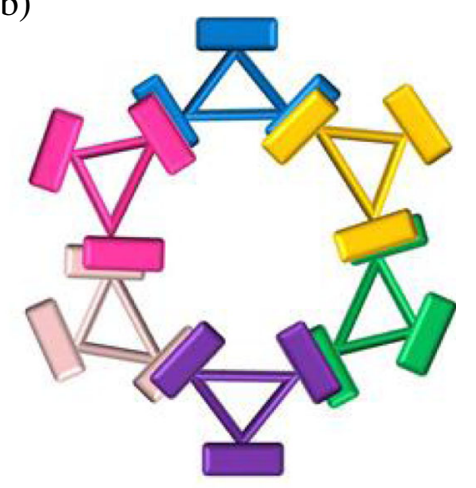

(c)

(a)

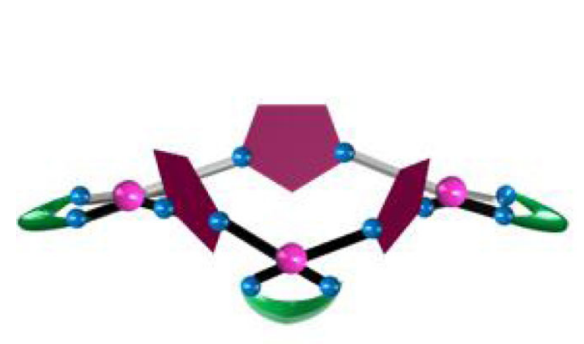

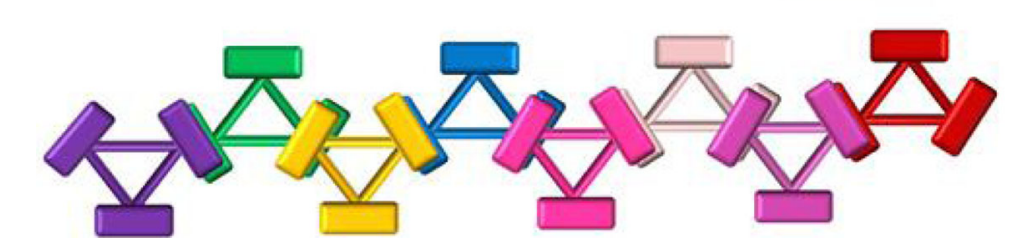

Figure 1. (a) Cartoon representation of the complexed cation part the selfassembled trinuclear complex $\left.\left[\mathrm{Pd}_{3}(\text { bpy })_{3} \text { (imidazolate }\right)_{3}\right]\left(\mathrm{NO}_{3}\right)_{3}, \mathbf{1}$ where the bound imidazolate units are oriented in a syn, syn, syn manner. (b)/(c) Selfassembly of the self-assembled trinuclear macrocycle utilizing $\pi-\pi$ stacking interactions to form circular, and infinite linear architectures. (Each triangular unit in (b)/(c) represents the core of the trinuclear macrocyclic molecule). 


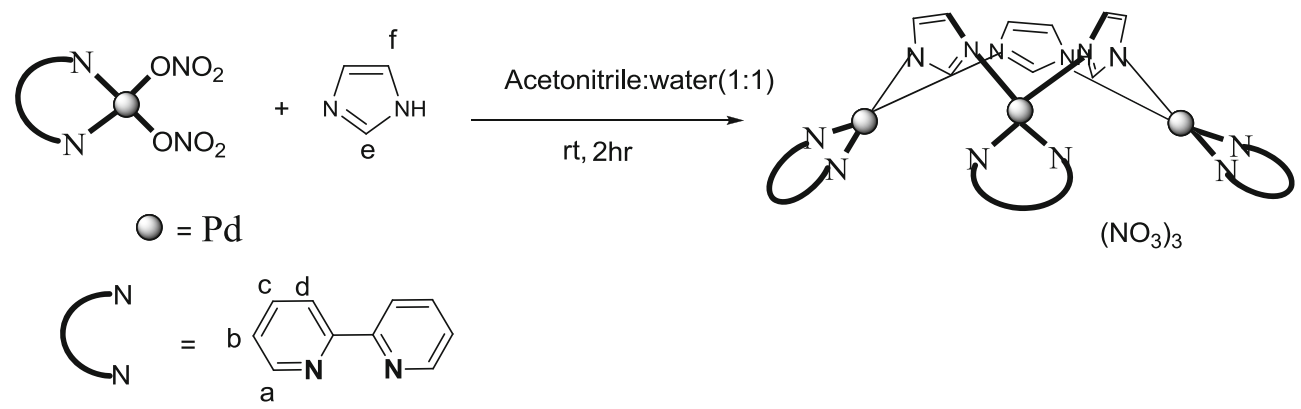

Scheme 1. Synthesis of the self-assembled trinuclear complex $\left.\left[\mathrm{Pd}(\mathrm{bpy})_{3} \text { (imidazolate }\right)_{3}\right]\left(\mathrm{NO}_{3}\right)_{3}, \mathbf{1}$.

obtained by slow evaporation of a solution of $\mathbf{1}$ in acetonitrile-water.

\subsection{Single crystal $x$-ray diffraction}

X-ray data collection was performed with a Bruker AXS Kappa Apex II CCD diffractometer equipped with graphite monochromated $\operatorname{Mo}(\mathrm{K} \alpha)(\lambda=0.7107 \AA)$ radiation. Crystal fixed at the tip of the glass fibre was mounted on the Goniometer head and was optically centred. The automatic cell determination routine, with 32 frames at three different orientations of the detector was employed to collect reflections and the programAPEX2-SAINT (Bruker, 2004) was used for finding the unit cell parameters. Four-fold redundancy per reflection was utilized for achieving good absorption correction using a multi-scan procedure. Besides absorption, Lorentz polarization and decay correction were applied during data reduction. The program SADABS was used for absorption correction using the multi-scan procedure. The structures were solved by direct methods using SHELXL-97 (Sheldrick, 1997) ${ }^{8}$ and refined by full-matrix least-squares techniques using SIR92 (WinGX) computer program. All hydrogen atoms were fixed at chemically meaningful positions and riding model refinement was applied Molecular graphics were generated using Mercury programs (version 3.3). The crystal data with refinement details are summarized in table 1.

\section{Results and Discussion}

The design of the complex $\left.\left[\operatorname{Pd}(\mathrm{bpy})_{3} \text { (imidazolate }\right)_{3}\right]$ $\left(\mathrm{NO}_{3}\right)_{3}, 1$ was envisioned considering the fact that imidazolate is a bent bidentate bridging ligand which upon complexation with the right-angled cis-protected $\operatorname{Pd}(\mathrm{II})$ component i.e., $\mathrm{Pd}(\mathrm{bpy})\left(\mathrm{NO}_{3}\right)_{2}$ should yield a cyclic trinuclear bowl type cage molecule. Spontaneous deprotonation of pyrazoles and also imidazoles is a known phenomenon as observed during their use as ligands for the preparation of coordination complexes. ${ }^{5 \mathrm{a}, \mathrm{b}, 9}$ The coordination vectors in imidazole derivatives subtend an angle of approximately around 150 degrees. ${ }^{10}$ Imidazole groups are likely to be orientated either in a syn, syn, syn (cone conformer) ${ }^{5 \mathrm{a}-\mathrm{c}}$ (figure 1) or syn, anti, anti (alternate conformer) ${ }^{10}$ fashion in the cages. Based on the predefined geometry and binding mode, the rigid non-linear bidentate imidazole ligand was considered as an ideal choice for the construction of a bowl type trinuclear molecule. In order to investigate the possible intermolecular interactions among such bowls, the $\pi$-surface containing cis-protecting unit such as bpy was considered to craft around the $\mathrm{Pd}(\mathrm{II})$. The reaction of cis- $[\mathrm{Pd}(\mathrm{bpy})]\left(\mathrm{NO}_{3}\right)_{2}$ with one equivalent of imidazole, $\mathbf{L} \cdot \mathbf{H}$ in acetonitrile: water (1:1) at room temperature over a period of $2 \mathrm{~h}$ lead to the formation of $\left[\mathrm{Pd}(\mathrm{bpy})_{3}(\mathbf{L})_{3}\right]\left(\mathrm{NO}_{3}\right)_{3}, \mathbf{1}$. This compound was prepared targeting fascinating intermolecular association in the solid-state, as shown in figure 1. It

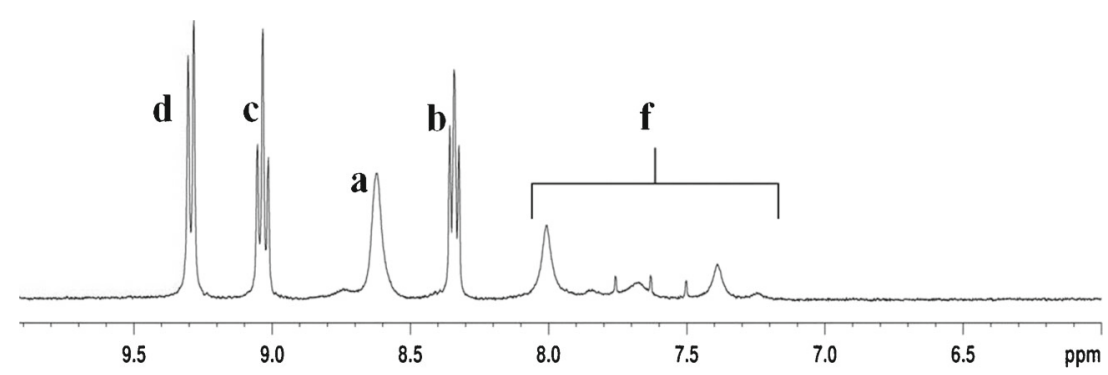

Figure 2. $500 \mathrm{MHz}{ }^{1} \mathrm{H}$ NMR spectrum in DMSO- $d_{6}(\mathrm{TMS}$ as external standard $)$ for $\left[\mathrm{Pd}_{3}(\text { bpy })_{3}(\text { imidazolate })_{3}\right]\left(\mathrm{NO}_{3}\right)_{3}, \mathbf{1}$. 
Table 1. Crystallographic data and structure refinement parameters of 1 (CCDC No. 989714).

\begin{tabular}{ll}
\hline Empirical formula & $\mathrm{C}_{39} \mathrm{H}_{33} \mathrm{~N}_{15} \mathrm{O}_{11} \mathrm{Pd}_{3}$ \\
Formula weight & 1207 \\
Crystal system & Monoclinic \\
space group & $\mathrm{C} 2 / \mathrm{c}$ \\
$a(\AA)$ & $26.180(2)$ \\
$b(\AA)$ & $25.241(2)$ \\
$c(\AA)$ & $15.4614(12)$ \\
$\alpha\left(^{\circ}\right)$ & 90 \\
$\beta\left(^{\circ}\right)$ & $119.006(3)$ \\
$\gamma\left({ }^{\circ}\right)$ & 90 \\
Volume $(\AA)^{3}$ & $8935.6(13)$ \\
$\mathrm{Z}$ & 8 \\
Wavelength $(\AA)$ & 0.71073 \\
Temperature $(\mathrm{K})$ & $173(2)$ \\
Calculated density $\left(\mathrm{g} / \mathrm{cm}^{3}\right)$ & 1.794 \\
Absorption coefficient $\left(\mathrm{mm}{ }^{-1}\right)$ & 1.271 \\
$\mathrm{~F}(000)$ & 4784 \\
Crystal dimensions (mm $)^{3}$ & $0.15 \times 0.10 \times 0.08$ \\
$\theta$ min/max (deg) & $1.20 / 21.04$ \\
Reflections collected / unique & $17034 / 4744[\mathrm{R}(\mathrm{int})=0.0694]$ \\
Data / restraints / parameters & $4744 / 12 / 613$ \\
Goodness-of-fit on $\mathrm{F}^{\wedge} 2$ & 1.010 \\
Final R indices [I $>2$ sigma(I) & $\mathrm{R} 1=0.0494, \mathrm{wR} 2=0.1298$ \\
$\mathrm{R}$ indices (all data) & $\mathrm{R} 1=0.1000, \mathrm{wR} 2=0.1616$ \\
Largest diff. peak and hole. $\mathrm{A}^{\wedge}$ & 0.93 and -0.55 \\
\hline & \\
\hline &
\end{tabular}

is expected to have $\pi-\pi$ stacking interactions since the cis-protecting unit i.e., bpy has $\pi$-surfaces. The intention of choosing cis-protecting unit like bpy was to sensibly study the importance of $\pi$-surface on crystal packing and analyze the overall packing in the structure. During this work, we observed a trinuclear macrocycle with syn, syn, syn conformation (cone conformer). Analysis of the crystal structures of the complex $\mathbf{1}$ revealed the anticipated intermolecular $\pi-\pi$ stacking interactions between planar bpy units present in 1. The complex $\left.\left[\mathrm{Pd}(\mathrm{bpy})_{3} \text { (imidazolate }\right)_{3}\right]\left(\mathrm{NO}_{3}\right)_{3}, \mathbf{1}$ displays the targeted packing where triangular molecules are arranged in a linear sequence depending on availability of $\pi$-surface as shown in figure 1b. A detailed description of the synthesis and the crystal structure of the complex are provided here.

\subsection{Synthesis and characterization of the $M_{3} L_{3}^{\prime} L_{3}$ type self-assembly}

The complex $\mathbf{1}$ is prepared by the combination of equimolar quantities of the ligand $\mathbf{L} \cdot \mathbf{H}$ with cis$[\operatorname{Pd}($ bpy $)]\left(\mathrm{NO}_{3}\right)_{2}$ in acetonitrile-water $(1: 1)$ at room temperature (scheme 1). A trinuclear complex of formula $\left.\left[\mathrm{Pd}(\text { bpy })_{3} \text { (imidazolate }\right)_{3}\right]\left(\mathrm{NO}_{3}\right)_{3}, \mathbf{1}$ was isolated in quantitative yield. The trinuclear complex is characterized by ${ }^{1} \mathrm{H} \mathrm{NMR},{ }^{13} \mathrm{C}$ NMR, $\mathrm{H}-\mathrm{H}$ COSY, HSQC,
ESI-MS (Supporting Information) and single crystal Xray diffraction (XRD) methods. The ${ }^{1} \mathrm{H}$ NMR spectrum of the complex have been recorded in DMSO- $d_{6}$ (figure 2). While the signals of the protons present in the bpy units are observed at expected positions, the signal due to $\mathrm{H}_{\mathrm{a}}$ was found to be broad. The imidazolate protons designated as $\mathrm{H}_{\mathrm{f}}$ appeared as broad signals spanning a range of $0.61 \mathrm{ppm}$. However, the protons designated as $\mathrm{H}_{\mathrm{e}}$ are probably merged inside the other signals. The NMR data indicates that in the solution state there is a slow conformational movement due to the possibility of formation of syn, syn, syn and syn, anti, anti- isomers and other intermediates. The formation of the trinuclear complex in the solution state was confirmed from ESI-MS data of the complex. The mass spectrum of 1 shows peaks at $m / z=329$ and 525 corresponding to $\left[\mathbf{1}-3 \mathrm{NO}_{3}\right]^{3+}$ and $\left[\mathbf{1}-2 \mathrm{NO}_{3}\right]^{2+}$, respectively.

\subsection{Crystal structure of 1}

Single crystals suitable for X-ray analysis were obtained for the complex 1. Details of the crystal structure are discussed in following sections. Analysis of the crystal structures revealed several intermolecular interactions. Two different views of the crystal structure of $\mathbf{1}$ are given in figure 3. The coordination geometry 
(a)

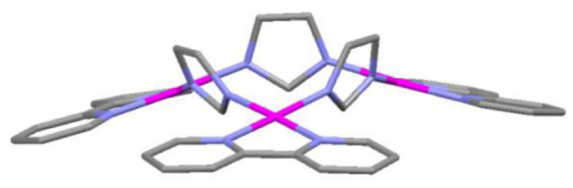

(b)

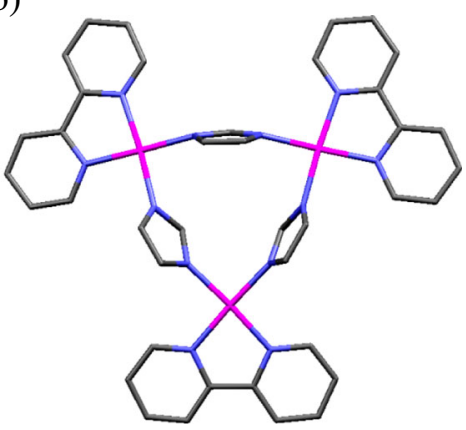

Figure 3. Crystal structure of the cationic fragment of the complex 1. Views along the axis: (a) parallel and (b) perpendicular to the imaginary triangle created by joining the three metal centres.

around the metal centres and the related bond lengths and bond angles in the structure are within the usual range. The three imidazolate units in the complex are oriented in a syn, syn, syn manner. Apparently the $\pi$-surface of the cis-protecting group and also the imidazolate protons are involved in significant intermolecular interactions which are discussed in a later section. The crystallographic parameters are listed in table 1.

\section{2a Crystal structure of $\left.\left[\mathrm{Pd}_{3}(\text { bpy })_{3} \text { (imidazolate }\right)_{3}\right]$} $\left(\mathrm{NO}_{3}\right)_{3}$ 1: Single crystals suitable for X-ray diffraction studies were obtained by slow evaporation of a solution of $\mathbf{1}$ in acetonitrile-water. The complex got crystallized in monoclinic space group $\mathrm{C} 2 / \mathrm{c}$. The structure is composed of one unit of $\left.\left[\mathrm{Pd}_{3}(\mathrm{bpy})_{3} \text { (imidazolate) }\right)_{3}\right]^{3+}$ cation and three nitrate ions. Two water molecules are also located in the structure. The crystal structure of 1 displays a bowl like molecular triangle (figure 3). The imaginary plane created by the three Pd(II) centres in the complex can be considered as the reference plane of the molecular triangle. The three Pd centres form an almost equilateral triangle with Pd-Pd nonbonded distances of 5.95, 5.96 and $5.97 \AA$. The dihedral angles between 'bpy' plane and the reference plane are 10.5810 .59 and $12.90^{\circ}$ indicating the bowl shape of the molecule. All the three bpy units are almost symmetrically disposed with respect to the reference plane. The three imidazolate moieties play the role of bridging ligands and are oriented in a syn, syn, syn manner (figure 3). Analogues trinuclear complexes derived from some imidazole derivatives are known to exist in syn, syn, syn form. ${ }^{5 \mathrm{a}-\mathrm{c}}$ These molecules can be considered as curved macrocycles and the structure possesses both concave and convex surfaces. The $\mathrm{C} 2$ carbon of the imidazolate moieties are pointed towards the concave side of the bowl. The dihedral angles between the bound imidazolate, $\mathbf{L}$ and the reference plane are $61.02,67.97$ and $84.09^{\circ}$. Thus, the three imidazolate units are not

(a)

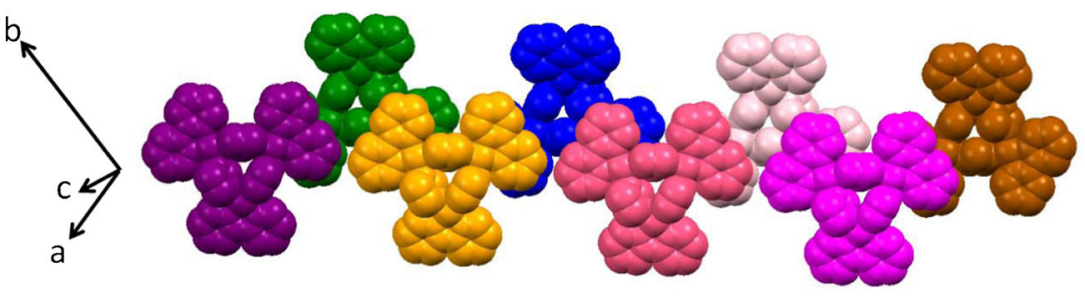

(b)

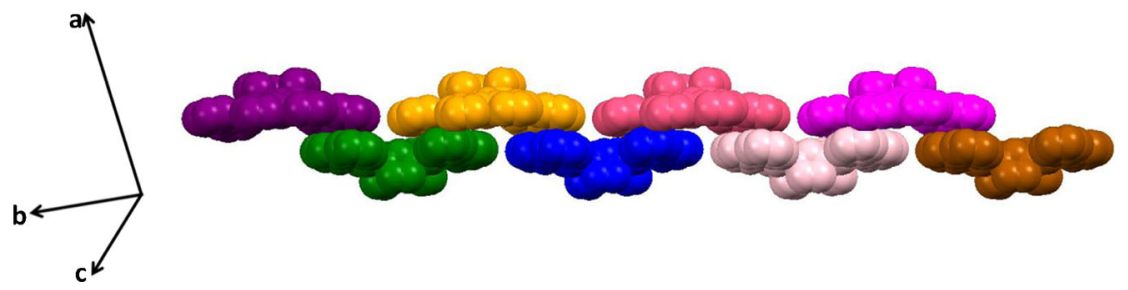

Figure 4. Two different views of chain like arrangement due to intermolecular $\pi-\pi$ interactions using the cationic part of the complex 1. 


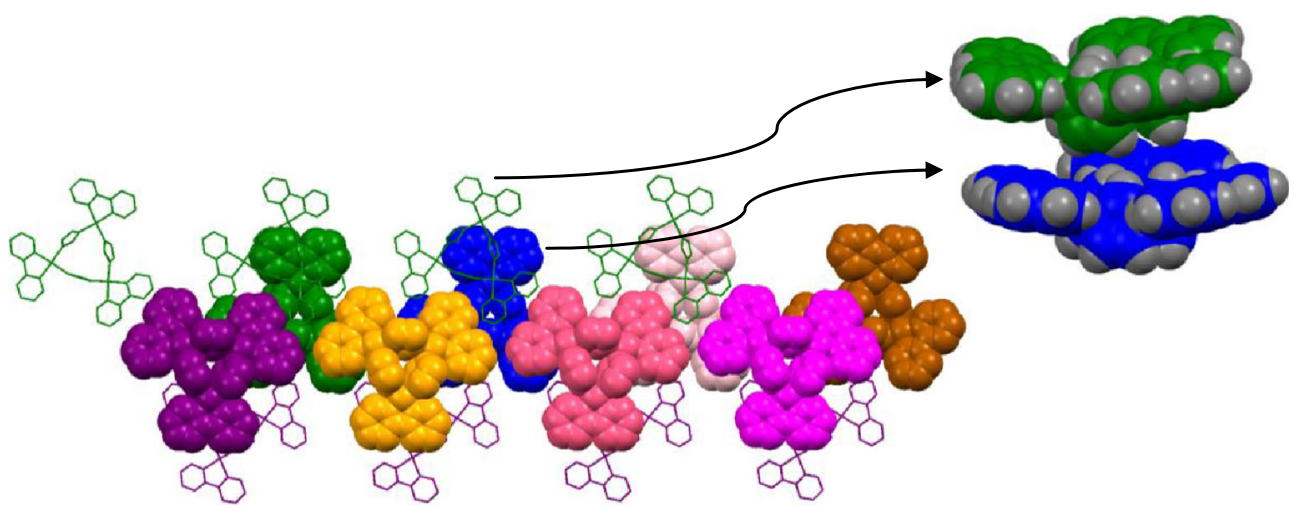

Figure 5. Packing diagram showing the $\mathrm{CH}-\pi$ interactions formed due to the $\pi$-surfaces of a chain with the relevant imidazolate hydrogen atoms of neighbouring bowls.

symmetrically disposed with respect to the reference plane. Arguably, one unit is disposed very differently from the other two.

The crystal structure of complex 1 exhibits intermolecular $\pi-\pi$ stacking interactions using the planar bpy components as shown in figure 4 . The $\pi$-surface of the bpy units located on the concave side of the bowls participated in the stacking. One molecule is stacked with two other neighbouring molecules by $\pi-\pi$ stacking interactions where upon the bpy units are stacked in a parallel displaced manner. Such parallel displaced stacking is usual for the association of two bpy moieties. ${ }^{4 a, b, 11}$ The distance between the two stacked bpy planes is $3.48 \AA$ which is similar to the ideal distance for $\pi-\pi$ stacking. The triangular units are thus arranged in a linear fashion to form a chain like array where the participation of one of the three bpy units of any given molecule is not required. The bpy units not involved in the chain formation are actually engaged with $\mathrm{CH}-\pi$ interactions with some of the imidazolate-based C4 and C5 hydrogen atoms of neighbouring bowls located above and below the relevant bpy planes as shown in figure 5 .

It is interesting to note that a chain is weakly connected to two neighbouring chains as shown in figure $6 a$ to form a wavy-bilayer like arrangement. Further arrangement of the bilayers one above the other in a slanted-stacked fashion happened to complete the molecular packing of the cationic part of the complex 1 in the crystal structure. The bilayers immediately above/below a given bilayer are very similar in the arrangement of the molecules as compared to the reference bilayer. However, the direction of the chain propagation is different. If the chains of a given bilayer are considered to propagate in horizontal lines, then the chains of the neighbouring bilayers are propagated in vertical lines as shown in figures $6 a$ and $6 \mathrm{~b}$. Thus the relative direction of the chain propagation is same (a)

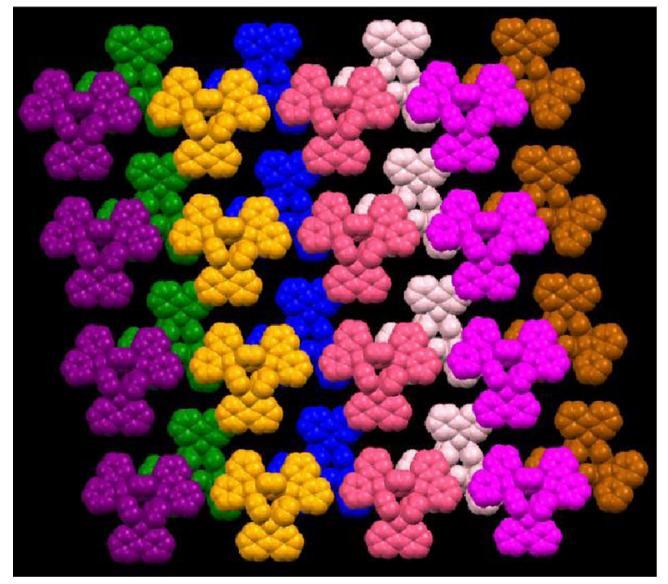

(b)

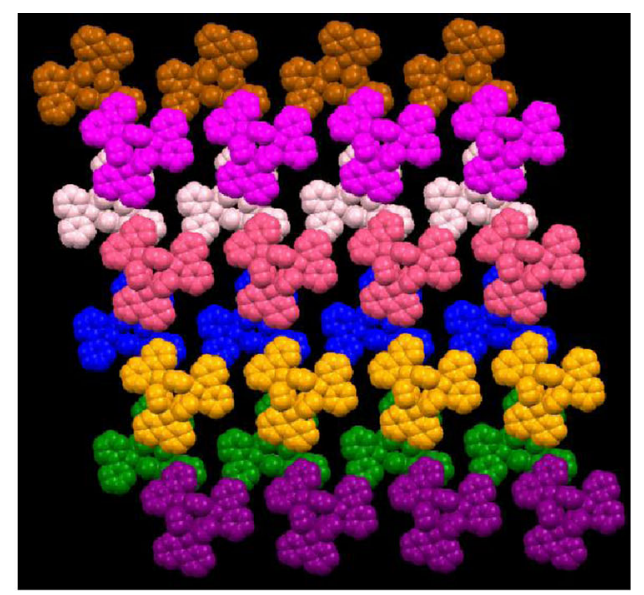

Figure 6. The arrangement of chains (a) in a given reference bilayer and (b) the neighbouring bilayer present above the reference one. 
in every alternate bilayer. A stacking of three bilayers is provided in the supporting information for further elaboration of the packing.

\section{Conclusion}

It is demonstrated that the presence of the $\pi$-surface in the cis-protecting group has significant influence on the packing behaviour of palladium(II)-based selfassembled macrocycles in the solid-state. The trinuclear bowl shaped molecule studied in this work display $\pi-\pi$ and $\mathrm{CH}-\pi$ interactions to make an interesting contribution to the crystal engineering.

\section{Supplementary Information}

The ${ }^{1} \mathrm{H}$ NMR, ${ }^{13} \mathrm{C}$ NMR, H-H COSY, HSQC, ESI-MS spectrum along with the relevant packing diagrams in the crystal structure of the complex $\mathbf{1}$ are provided. Xray crystallographic data in CIF format for the structure of $\mathbf{1}$ is also included. These are available free of charge at www.ias.ac.in/chemsci.

\section{Acknowledgements}

We thank DST, India (Project No. SB/S1/IC-05/2014) for providing financial support to our research endeavours. We gratefully acknowledge the single crystal Xray diffractometer facility funded by IIT Madras.

\section{References}

1. (a) Cook T R, Zheng Y-R and Stang P J 2013 Chem. Rev. 113 734; (b) Debata N B, Tripathy D and Chand D K 2012 Coord. Chem. Rev. 256 1831; (c) Chakrabarty R, Mukherjee P S and Stang P J 2011 Chem. Rev. 111 6810; (d) Leininger S, Olenyuk B and Stang P J 2000 Chem. Rev. 100 853; (e) Kumar G and Gupta R 2013 Chem. Soc. Rev. 42 9403; (f) Han M, Engelhard D M and Clever G H 2014 Chem. Soc. Rev. 43 1848; (g) Ward M D and Raithby P R 2013 Chem. Soc. Rev. 421619

2. (a) Desiraju G R 2000 J. Chem. Soc., Dalton Trans. 3745; (b) Desiraju G R 2011 Cryst. Growth Des. 11 896; (c) Beatty A M 2003 Coord. Chem. Rev. 246131
3. Janiak C 2000 J. Chem. Soc., Dalton Trans. 3885

4. (a) Naranthatta M C, Das D, Tripathy D, Sahoo H S, Ramkumar V and Chand D K 2012 Cryst. Growth Des. 12 6012; (b) Tripathy D, Ramkumar V and Chand D K 2013 Cryst. Growth Des. 13 3763; (c) Krishna Kumar D, Das Amitava and Dastidar P 2006 Cryst. Growth Des. 6 216; (d) Navarro J A R, Romero M A and Salas J M 1997 J. Chem. Soc., Dalton Trans. 1001

5. (a) Liu L-X, Huang H-P, Li X, Sun Q-F, Sun C-R, Li Y-Z and Yu S-Y 2008 Dalton Trans. 1544; (b) Ning G-H, Xie T-Z, Pan Y-J, Li Y-Z, Yu S-Y 2010 Dalton Trans. 39 3203; (c) Tzeng B-C, Kuo J-H, Lee Y-C and Lee G-H 2008 Inorg. Chim. Acta 361 2515; (d) Yu S-Y, Huang H, Liu H-B, Chen Z-N, Zhang R and Fujita M 2003 Angew. Chem., Int. Ed. 42 686; (e) Qin Z, Jennings M C and Puddephatt R J 2001Chem. Commun. 2676; (f) Ghosh S, Turner D R, Batten S R and Mukherjee P S 2007 Dalton Trans. 1869; (g) Li S-H, Huang H-P, Yu S-Y, Li Y-Z, Huang H, Sei Y and Yamaguchi K 2005 Dalton Trans. 2346; (h) Qin Z, Jennings M C and Puddephatt R J 2002 Inorg. Chem. 41 3967; (i) Teo P, Koh L L, Hor T S A 2008 Inorg. Chem. 47 6464; (j) Bar A K, Chakrabarty R, Chi K-W, Batten S R and Mukherjee P S 2009 Dalton Trans. 3222; (k) Steffen A, Braun T, Neumann B and Stammler H-G 2007 Angew. Chem., Int. Ed. 468674

6. (a) Fujita M, Sasaki O, Mitsuhashi T, Fujita T, Yazaki J, Yamaguchi K and Ogura K 1996 Chem. Commun. 1535; (b) Diaz P, Tovilla J A, Ballester P, Benet-Buchholz J and Vilar R 2007 Dalton Trans. 3516; (c) Ghosh S and Mukherjee P S 2009 Inorg. Chem. 482605

7. (a) Wimmer S and Castan P1989 J. Chem. Soc., Dalton Trans. 403; (b) Drew H D K, Pinkard, F W, Preston G H and Wardlaw W 1932 J. Chem. Soc. 1895

8. Sheldrick G M SHELX 971997 Programs for Crystal Structure Analysis (Release 97-2); University of Gottingen: Gottingen, Germany

9. (a) Yu S-Y, Jiao Q, Li S-H, Huang H-P, Li Y-Z, Pan Y-J, Sei Y and Yamaguchi K 2007 Org. Lett. 9 1379; (b) Yu S-Y, Huang H-P, Li S-H, Jiao Q, Li Y-Z, Wu B, Sei $\mathrm{Y}$, Yamaguchi K, Pan Y-J and Ma H-W Inorg. Chem. 200544 9471; (c) Steffen A, Braun T, Neumann B and Stammler H-G 2007 Angew. Chem., Int. Ed. 1198828

10. Lai S-W, Chan M C-W, Peng S-M and Che C-M 1999 Angew. Chem., Int. Ed. 38669

11. (a) Tong M L, Lee H K, Chen X M, Huang R B and Mak T C W 1999 J. Chem. Soc., Dalton Trans. 3657; (b) Janiak C, Deblon S, Wu H P, Kolm M J, Klufers P, Piotrowski H and Mayer P 1999 Eur. J. Inorg. Chem. 1507; (c) Gao E, Zhu M, Yin H, Liu L, Wu Qi and Sun Y J 2008 Inorg. Biochem. 1021958 